\title{
O PAPEL DAS POLÍTICAS PÚBLICAS NA CONSTRUÇÃO DO ESTADO SOCIOAMBIENTAL
}

\author{
THE ROLE OF PUBLIC POLICY IN THE CONSTRUCTION OF STATE \\ ENVIRONMENTAL
}

Jerônimo Giron *

\begin{abstract}
Sumário: Introdução; 1 Estado de Direito e sua reconfiguração; 2 Políticas Públicas, o problema público e o meio ambiente; 3 Plano Nacional e contextualização; Considerações finais; Referências.

Resumo: O Estado é uma entidade detentora de responsabilidades frente aos cidadãos. Com o passar do tempo estas foram se modificando. Na atualidade, além dos tradicionais direitos individuais e sociais, o Estado passou a dedicar atenção aos direitos difusos, englobando com especial ênfase aqueles referentes ao meio ambiente. Assim, com o objetivo de atuar sobre essa seara, o Estado utiliza-se de diversos mecanismos, dentre os quais as políticas públicas. Tendo a noção da importância do meio ambiente e que determinados fatos a ele concernentes podem ser configurados como problemas públicos, cabe ao Estado definir práticas que sejam eficazes. Dessa forma, neste trabalho suscita-se a discussão sobre essa possível reconfiguração das responsabilidades do Estado e da utilização de políticas públicas para abarcar tal fato, com especial atenção à área ambiental, tendo a estruturação de um Plano Nacional de Meio Ambiente como baluarte de atuação do Estado em face dessa temática.

Palavras-chave: Políticas Públicas. Problema Público. Meio Ambiente. Estado. Plano Nacional.
\end{abstract}

\begin{abstract}
The State is an entity which have responsibilities front of citizens. With the time that responsibilities have changed. Today, beyond the traditional individual rights and social, the State has dedicated attention for the diffuse rights, encompassing with special emphasis those rights linked of environment. Thus, in order to act on that field, the state makes use of several mechanisms, among which public policies. By understanding the importance of the environment and that certain facts pertaining to it can be configured as public problems, the state must define effective pratices. Thus, in this work want created a discussion about possible reconfiguration of the responsibilities of the State and the use of public policies for execute this act, with special attention the environment field, having the organization of the National Plane of Environment how bastion of the performance the State in face of this theme.

Key words: Public Policies. Public Problems. Environmet. State. Nacional Plane.
\end{abstract}

\section{INTRODUÇÃO}

O tema meio ambiente está em voga. Atualmente, discute-se tal matéria em diversos setores da sociedade: na academia - Universidade e Centros de Pesquisas -; nas escolas de ensino fundamental e médio; nas empresas privadas; nas conversas informais; bem como no setor público.

Os motivos para tais discussões relacionam-se com diversos fatores, dentre os quais o temor de que as ações dos homens sobre o meio ambiente - exploração dos recursos naturais para a sobrevivência do ser humano e produção de artefatos para a manutenção do mercado e de determinado grau de conforto material - possam estar acarretando efeitos que direta ou indiretamente irão afetar a qualidade de vida de todos os seres humanos, bem como a duração da existência deles. Embora não exista consenso sobre as suas causas - naturais ou humanas - a alteração climática é exemplar.

Percebe-se que diversas instituições, além de discutir questões atinentes ao meio ambiente também estão interessadas em refletir sobre ações práticas com o objetivo de tentar arrefecer alguns desses possíveis efeitos lesivos provocados pelos seres humanos sobre a natureza. Algumas empresas privadas desenvolvem seus produtos baseados em protocolos de qualidade que privilegiam a gestão dos recursos ambientais; alguns cidadãos preocupam-se em separar adequadamente o lixo; agricultores buscam preservar as áreas de preservação permanente, bem como manter a

\footnotetext{
${ }^{*}$ Mestrando em Direito Ambiental pela Universidade de Caxias do Sul/RS - UCS.
} 
reserva legal de suas propriedades intactas; o poder público institui a licitação ambiental, ou seja, ações isoladas estão sendo realizadas.

Dessarte, nota-se que ações estão sendo praticadas, contudo, cabe a cada cidadão suscitar novas práticas, tanto individuais como sociais. Vive-se em um Estado Democrático de Direito, todavia, tal concepção está migrando para um Estado Socioambiental de Direito, assim, cabe aos integrantes desse novo cenário - agentes políticos e sociedade -, criar mecanismos que possam estabelecer práticas em prol da defesa do meio ambiente, que, caso não sejam implementadas de imediato, ao menos permitam a discussão e o esclarecimento sobre diversos tópicos que envolvem a perspectiva ambiental. Para tal consecução propõe-se a criação de um Plano Nacional de Meio Ambiente.

Nessa linha, cabe destacar que as políticas públicas possuem o intuito de resolver problemas públicos. Embora não seja algo aparente, o meio ambiente pode ser entendido como um elemento a ser tratado pelo Poder Público, uma vez que as agressões sobre ele impetradas podem repercutir na existência dos seres humanos. Assim, deve-se usar os instrumentos das políticas públicas para motivar que os homens preservem os recursos naturais.

Esta comunicação visa discutir alguns aspectos conceituais sobre a concepção do Estado, não mais entendido como uma entidade voltada apenas à escrituração de direitos de primeira e segunda geração, mas também como instituição que se volta para a consecução de direitos de terceira geração, ou seja, os ditos direitos difusos. Além disso, pretende discutir o que seja um problema público, vinculando tal perspectiva à seara ambiental, propondo ao final, com cunho eminentemente teórico, a construção de um Plano Nacional de Meio Ambiente como instrumento para traçar objetivos e metas para que os agentes políticos e cidadãos garantam a melhoria das condições dos recursos naturais e consequentemente da vida do homem.

\section{ESTADO DE DIREITO E SUA RECONFIGURAÇÃO}

O Estado moderno, como entidade representativa e gestora de responsabilidades frente aos cidadãos, possui uma evolução histórica recente. $\mathrm{O}$ ideário do Estado Democrático de Direito surge com a Revolução Francesa. Desde aquele período até os dias atuais, talvez por estar aliado a primados que incentivaram o individualismo - laissez-faire -, sustentou-se basicamente uma gama de direitos individuais, especialmente o concernente à liberdade, com sutis vínculos coletivos quando da construção dos preceitos da fraternidade e da igualdade.

Não apenas de percepções individuais se sustenta o homem, sendo que outras noções foram assimiladas pelo Estado, como a criação dos direitos sociais, chegando atualmente nos direitos difusos. Da configuração desses novos direitos são desenvolvidas diversas discussões conceituais que propõem uma modificação da concepção do Estado, não mais o entendendo como Democrático de Direito, mas sim como Socioambiental de Direito.

Nessa linha de construção do Direito - base de sustentação do Estado -, cabe ressaltar que valores sociais e aspectos culturais são algumas das bases para seu desenvolvimento. Assim, verifica-se a proeminência do antropocentrismo como norte para a estruturação do direito.

[...] todo desenvolvimento social se verifica sob um enfoque exclusivamente antropocêntrico, e é também sob este mesmo enfoque que se desenvolve, posteriormente, todo o Direito, o que não se poderia esperar que fosse de modo diverso, vez que este e o paradigma ainda hoje adotado pela sociedade, 
e o Direito apenas reflete os valores da sociedade que o construiu. (FRANCO, 2005, p.28).

No entanto, tal fato deve ser repensado, suscitando a proposição de novos valores, mesclando assim, a indispensável reflexão sobre o homem com ponderações vinculadas à natureza. Nessa linha, - antes mesmo da discussão sobre a estruturação de um novo conceito para o Estado -, discutiu-se no passado a concepção de um novo ramo do direito, qual seja o direito ambiental, que incentivou estudos, proporcionando à noção antropocêntrica outros focos de pensamento, vinculando o homem aos diversos elementos que existem no seu entorno e não somente com outros seres humanos.

Consoante Azevedo (2008, p. 99), o surgimento do direito ambiental liga-se a ideia de defesa e preservação da vida, como também de todos os valores que a permeia, sendo a Convenção de Estocolmo o marco inicial do novel ramo do direito.

Ainda, de acordo com Benjamin, o direito ambiental surge no seio da sociedade industrial, tendo por protagonista a degradação ambiental. Para ele, sociedade e ambiente não podem se desvincular, pois somente dessa forma criar-se-á um quadro compatível para a perpetuação da existência humana. (FENSTERSEIFER, 2008, p. 95).

Percebe-se que antes mesmo das cartas magnas assimilarem noções ambientais, o direito ambiental já era debatido. Tal fato motivou que as constituições de diversos países incluíssem a matéria ambiental em seus textos. No Brasil não foi diferente, sendo que somente com a promulgação da Constituição da República Federativa do Brasil, 05 de outubro de 1988, houve a inclusão expressa do tema meio ambiente no corpo da Lei Maior.

Embora seja ressaltado constantemente o vínculo social no teor dos dispositivos da Constituição Federal, o tema ambiental é premente. Nota-se que na Constituição Federal de 1988 há indícios da concepção do Estado Socioambiental de Direito. Ressalta-se que essa alternativa propõe que os agentes representativos do Estado atuem, refletindo sobre a situação humana, quando da tomada de decisão, pautado por princípios de natureza ecológica. "No Estado Socioambiental de Direito, as decisões e ações políticas são orientadas e determinadas a partir de um filtro constitucional de valores e de princípios de natureza ecológica". (Idem, p. 124).

Canotilho, discutindo essa nova estrutura estatal, evidencia que a administração pública deverá atuar de maneira integrativa, tendo como paralelo um direito ambiental integrativo. Democratizar a democracia, motivando a promoção da qualidade ambiental. O meio ambiente deverá ser entendido pela administração pública como algo maior, não apenas como aquilo que está fora, mas sim como aquilo que auxilia na consecução dos objetivos do Estado.

Integrar os cidadãos e as suas organizações nas estratégias regulativas do ambiente representa, afinal, uma das dimensões indispensáveis a concepção integrativa do ambiente, sob pena de esta concepção se transformar num encapuçado plano global do ambiente, sem quaisquer comunicações com o ambiente humano e social. (CANOTILHO, 2003, p. 505).

Por tudo isso, tendo em vista essa nova percepção sobre as preocupações do Estado propõe-se a implementação de políticas públicas voltadas a preservação/conservação do meio ambiente, provocando a interação entre as necessidades humanas com a perspectiva ambiental, motivando dessa forma a integração entre o homem e a natureza. Contudo, antes de propor algum instrumento, cabe esclarecer algumas características sobre as políticas públicas, em especial sobre o problema público. 


\title{
2 POlíticas Públicas, O PROBlema PÚblico E O MEIO AMBIENTE
}

Um dos temas mais debatidos pela humanidade, talvez seja: o que é política, o que representa e qual a sua finalidade. Assim, é relevante atentar para algumas ponderações sobre ela.

Para Secchi, tendo por base as teorizações de Bobbio,

\begin{abstract}
Politics, na concepção de Bobbio (2002), é a atividade humana ligada a obtenção e manutenção dos recursos necessários para o exercício do poder sobre o homem. [...]

O segundo sentido da palavra "política" é expressado pelo termo policy em inglês. Essa dimensão de "política" é a mais concreta e a que tem relação com orientações para a decisão e ação. (SECCHI, 2010, p. 01).
\end{abstract}

Percebe-se que o termo política possui diversas conotações, sendo que há uma convergência: mediar relações de poder. Quanto às políticas públicas, tem-se que esse conceito se direciona para a tomada de decisões, ou seja, na solução de determinados problemas. Consoante Saravia (2006, p. 28) as políticas públicas tratam de fluxos de decisões públicas, orientada para a manutenção do equilíbrio social, ou introduzir desequilíbrios para modificar determinada realidade.

Ampliando a percepção do que seja uma política pública, bem como ponderando sobre suas características, verifica-se:

\begin{abstract}
Nas definições dos dicionários de ciência política, encontram-se os seguintes componentes comuns: a) institucional: a política é elaborada ou decidida por autoridade formal legalmente constituída no âmbito da sua competência e é coletivamente vinculante; b) decisório: a política é um conjunto-sequência de decisões, relativo à escolha de fins e/ou meios, de longo ou curto alcance, numa situação específica e como resposta a problemas e necessidades; c) comportamental, implica ação ou inação, fazer ou não fazer nada; mas uma política é acima de tudo, um curso de ação e não apenas uma decisão singular; d) causal: são os produtos de ações que têm efeitos no sistema político e social. (SARAVIA, 2006, p. 31).
\end{abstract}

A política pública está afeita à tomada de decisão, e que dessa devem partir efeitos sobre o tecido social, "Entende-se por política pública (public policy) o conjunto coerente de decisões, de opções e de ações que a administração pública leva a efeito orientada para uma coletividade e balizada pelo interesse público". (BERGUE, 2011, p. 508).

Embora possa se dirigir a soluções específicas e pontuais que tenha efeito direto sobre determinado segmento social - caso do Programa Bolsa Família (famílias carentes) - a finalidade de uma política pública é melhorar as condições da sociedade em geral. Contudo, as políticas públicas surgem do engenho mental/criativo dos gestores públicos ou existe algum outro motivador?

Em regra o que estimula a formulação/implementação/execução de políticas públicas é um problema público. Pelas palavras de Secchi, o problema público é o elemento motivador e essencial para a criação de uma política pública. (SECCHI, 2010, pp. 02 e 04$)$.

Logo, percebe-se que a essência da política pública recai sobre a percepção de um problema público, que, caracteriza-se por ser um fato que implica em uma 
quantidade ou qualidade de pessoas, que se torna um problema, quando os atores políticos o consideram como tal. Esse contexto é explanado por Sechi:

A definição do que seja um "problema público" depende da interpretação normativa de base. Para um problema ser considerado "público", este deve ter implicações para uma quantidade ou qualidade notável de pessoas. Em síntese, um problema só se torna público quando os atores políticos intersubjetivos o consideram problema (situação inadequada) e público (relevante para a coletividade). (2010, pp. 07-08).

Existindo a percepção do que seja um problema público e tendo noção da importância que ele tem para a formulação de políticas públicas, cabe destacar que eles não podem ser entendidos apenas objetivamente, mas sim subjetivamente, pois dessa forma melhores perspectivas poderão ser refletidas para solucioná-los. "El mundo de los problemas estará, pues, en directa relación con el mundo de lás soluciones, ya que muchas veces diferentes soluciones se refieren de hecho a distintos problemas". (SUBIRATS, 2006, p. 200).

Assim, subvertendo a noção objetiva dos problemas públicos, pode-se atentar que o meio ambiente, pelo menos atualmente, pode ser tratado como tal, pois as alterações realizadas sobre seus recursos e serviços estão prejudicando direta e indiretamente a existência dos seres humanos. A defesa do meio ambiente é relevante, pois se trata de algo importante à coletividade.

Um estudo de políticas públicas não prescinde do estudo de um problema que seja entendido como coletivamente relevante. Sjöblom (1984) dá uma definição prática para "problema": a diferença entre a situação atual e uma situação ideal possível. Um problema existe quando o status quo é considerado inadequado e quando existe a expectativa do alcance de uma situação melhor. (SECCHI, 2010, p. 07).

Constata-se que os problemas ambientais, não são apenas considerados como adversidades do meio ambiente, mas muito mais do que isso são também sociais, ou seja, humanos. Beck (2010, p. 99) referenda tal perspectiva, pois acredita que a própria evolução histórico-social do ser humano provoca alterações sobre o meio ambiente.

Nessa perspectiva, cabe esclarecer que existem ações entendidas como políticas ambientais, contudo, as práticas que elas promovem são frágeis, sem metas ou objetivos amplos, especialmente por serem ações baseadas na resolução de sintomas em curto prazo. Da mesma forma que baixar a febre não significa a cura de uma infecção. Consoante Leipert,

\footnotetext{
"A política ambiental tradicional, fundamentalmente voltada ao combate de sintomas e a preocupações objetivas, não pode satisfazer no longo prazo nem a critérios ecológicos nem a critérios econômicos. De um ponto de vista ecológico, ela em última medida corre invariavelmente atrás dos processos produtivos prejudiciais ao meio ambiente que se antecipam a ela [...] Uma razão decisiva poderia provavelmente ser encontrada no fato de que a política ambiental tradicional é implementada ao final do processo produtivo, e não no início, quer dizer, no momento em que se selecionam as tecnologias, as instalações, as matérias-primas, os insumos e os combustíveis dos produtos a serem produzidos [...]" (BECK, 2010, p. 86).
}

Verifica-se que existem dificuldades em determinar o momento em que uma política voltada à proteção ambiental deve atuar. Além da dificuldade de sua implementação, ressalta-se que parte da população, estimulada pelos meios de 
comunicação, descrê das ações da categoria política, assim, pode-se dizer que, especialmente no Brasil, a política está em crise, pois ela parece não mais trabalhar pelo e para o povo, mas sim para personagens avulsos - instituições privadas, determinados setores da sociedade -. "O jogo político torna-se a cada dia mais cínico. A desconformidade entre o dito e o feito atinge proporções alarmantes. A democracia pouco importa às forças econômico-financeiras. O que interessa é a fidelidade aos dogmas econômicos estabelecidos. [...]”. (AZEVEDO, 2008, p. 17).

Desse descrédito, ocorrem repercussões sobre o direito positivado, fazendo com que as leis pareçam mais recortes de normas do que efetivamente disposições que almejem regulamentar práticas sociais ou preservar direitos da sociedade como um todo, visto que perdem a força moral e apenas aparentam ser instrumentos efetivos. (AZEVEDO, 2008, p. 42).

Assim, cria-se um ambiente de incerteza, fato esse prejudicial à construção de políticas públicas, contudo, tais fatos não devem impedir seu desenvolvimento, pois mesmo em um ambiente de insegurança ela deve ser adaptável, motivando uma constante atuação do Estado sobre a sociedade. "[...] É claro que as organizações públicas continuarão a funcionar em um ambiente de incerteza, imprevisibilidade e complexidade crescentes é a chave para o sucesso futuro na contribuição para melhor formulação de políticas é a capacidade de se adaptar e de se ajustar". (BRYNER, 2010, p. 331)

Mesmo com esse ambiente de instabilidade (KLIKSBERG, 2009, p. 450), cabe evidenciar que existem leis que teorizam sobre políticas públicas voltadas ao meio ambiente. artigo

da Lei n. ${ }^{\circ}$ 6.938, de 31 de agosto de 1981, que dispõe sobre a Política Nacional do Meio Ambiente, seus fins e mecanismos de formulação e aplicação, e dá outras providências, retrata que as suas diretrizes serão formuladas em normas e planos.

Outra legislação, a Lei n. ${ }^{\circ}$ 9.795, de 27 de abril de 1999, que dispõe sobre a educação ambiental, institui a Política Nacional de Educação Ambiental e dá outras providências, retrata no artigo $3^{\mathrm{o}^{2}}$ que a educação ambiental deverá ser definida por meio de políticas públicas.

Dessa forma, nota-se que algumas leis esparsas talham a ideia de que políticas públicas voltadas ao domínio ambiental devem ser estruturadas.

Por conseguinte, para motivar a criação de um cenário de maior comprometimento e que esteja vinculado à noção de planejamento, similar ao que se verifica em instituições privadas, contextualiza-se sobre a elaboração de um Plano Nacional de Meio Ambiente, que estabeleça metas estimulantes à conservação/preservação de parte dos recursos naturais, bem como dos serviços ambientais, outorgando maior segurança jurídica à tomada de decisão dos gestores públicos e credibilidade frente à sociedade quando da sua divulgação.

\section{PLANO NACIONAL E CONTEXTUALIZAÇÃO}

Para a elaboração de um plano é necessário compreender o que seja planejamento. Consoante Oliveira (2006, p. 199), o planejamento evoluiu nos últimos cem anos. Essencialmente, ele surgiu com o escopo de organizar os centros urbanos, sendo o planejamento uma função técnica pautada por urbanistas e arquitetos.

Assimilando as ideias inicialmente propostas para a organização dos centros urbanos, a noção de planejamento foi absorvida pela política. Numa análise específica do caso brasileiro, o citado Autor evidencia que o planejamento no Brasil sempre esteve ligado a noções de controle e de previsibilidade. 
No Brasil, planejamento sempre esteve ligado à elaboração de planos e de controle. Através da história, verificamos a quantidade de planos, que já foram e continuam sendo elaborados: planos trienais, planos decenais, planos econômicos, planos plurianuais, planos de desenvolvimento regionais, planos diretores etc. Temos uma cultura de planos, com a idéia de antever e organizar o futuro (como se fosse possível fazer isso de maneira racional) a idéia de controle também está presente. (OLIVEIRA, 2006, p. 198).

Ele entende que existe uma visão deturpada acerca do planejamento, pois ele é elaborado por corpos técnicos, que após seu desenvolvimento, não possuem a devida competência para encaminhar de forma conveniente sua implementação. Assim, essa fase é prejudicada, visto que a construção inicial é boa, todavia a execução é falha. (OLIVEIRA, 2006, p. 189).

Nessa linha é relevante atentar para o processo, ou seja, o planejamento deve nortear os agentes políticos, mas não deve ser ele o baluarte de atuação, mas apenas um instrumento para a consecução de maneira mais organizada de determinado fim.

Na realidade, o estudo de implementação requer um entendimento de sua complexidade e de sua interação com o processo de planejamento. $\mathrm{O}$ resultado de um processo de planejamento, incluindo sua implementação, tem de ser visto como uma sequência de eventos aparentemente simples, mas que dependem de uma cadeia complexa de interações recíprocas para que obtenham o esperado, e muitas vezes essa cadeia não pode ser prevista ou controlada. (OLIVEIRA, 2006, p. 193).

Percebe-se que Oliveira apresenta ressalvas à noção de planejamento, tendo em vista as ações equivocadas praticadas no passado. Cabe destacar que, mesmo que o planejamento demonstre equívocos, e que a implementação seja complexa, por intermédio da recursividade, podem os agentes interessados em efetivar tal prática reformular suas ações com o objetivo de atingir o fim colimado pela política pública.

\begin{abstract}
A implementação é a continuação da formulação de políticas, mas com novos atores, procedimentos e ambientes institucionais. A medida que os esforços de implementação prosseguem, tornamo-nos conscientes de novos problemas, restrições e oportunidades. Recursos e objetivos são invariavelmente instáveis. Conseqüências inesperadas permeiam os esforços de implementação de políticas [...]. (BRYNER, 2010, p. 319).
\end{abstract}

Por conseguinte, constata-se que o planejamento pode ser entendido como uma ferramenta que antevê o futuro e busca de tal maneira evitar que determinadas ações não ocorram ou incentiva que determinadas práticas sejam realizadas. Pfaffenseller (2011, pp. 111-112), diante dos ensinamentos de Canotilho, pondera sobre a perspectiva essencial do planejamento, expondo que o Estado deve compartilhar responsabilidades, em especial no instante em que seus agentes devam tomar decisões.

Como exemplo, a mesma Autora menciona algumas ações a serem efetivadas em respeito àquilo que dispõe Plano Plurianual 2008-2011.

Com foco na instituição de uma gestão pública ambiental solidária e responsável, o Plano Plurianual 2008-2011 (Lei 11.653/2008) instituiu, dentre inúmeros outros, dois importantes programas governamentais voltados à proteção ambiental:

(a) Programa 0052 - Educação Ambiental para Sociedades Sustentáveis 
Objetivo: Construir valores e relações sociais, conhecimentos, habilidades, atitudes e competências que contribuam para a participação de todos na edificação de sociedades sustentáveis.

(b) Programa 1102 - Agenda 21

Objetivo: Promover a internalização dos princípios e estratégias da Agenda 21 Brasileira na formulação e implementação de políticas públicas nacionais e locais para estabelecer as prioridades a serem executadas em parceria governo-sociedade, na perspectiva de constituição de sociedade sustentáveis. (pp. 115-116).

Conclui-se, dessa maneira, que o planejamento é o instrumento basilar para a consecução de um Plano. Nesse sentido deve-se destacar qual a relevância dos Planos.

A justificativa inicial para a estruturação de um Plano Nacional de Meio Ambiente está no bem-estar social que pode estimular.

Para além de um bem-estar individual e social, as construções jurídicoconstitucionais caminham hoje no sentindo de garantir ao indivíduo e à comunidade como um todo desfrute de um bem-estar ambiental, ou seja, de uma vida saudável com qualidade ambiental, o que se apresenta como indispensável ao pleno desenvolvimento da pessoa e ao desenvolvimento humano no seu conjunto. (SARLET; FENSTERSEIFER, 2010, p. 12).

Além de motivar a consecução dos deveres estatais, o Plano poderia estimular que a população reflita sobre o meio ambiente, possibilitando um real conhecimento sobre ele, bem como sobre as considerações da lei sobre tal matéria, em especial a Constituição, uma vez que a Carta Magna evidencia que o meio ambiente se refere a um direito fundamental. (FENSTERSEIFER, 2008, pp. 78-79).

Ratificando a ideia de que a estruturação de um Plano Nacional de Meio Ambiente é salutar, Beck, reformula a concepção deturpada de que a natureza se opõe à sociedade.

[...] A oposição entre natureza e sociedade é uma construção do século XIX, que serve ao duplo propósito de controlar $e$ ignorar a natureza. A natureza foi subjugada e explorada no final do século XX e, assim, transformada de fenômeno externo interno, de fenômeno predeterminado em fabricado. Ao longo de sua transformação tecnológico-industrial e de sua comercialização global, a natureza foi absorvida pelo sistema industrial. (BECK, 2010, p. 09).

O Direito deveria possuir uma intervenção maior, não apenas de maneira coativa, mas também programática. Porque se a maioria das empresas privadas planeja suas ações, porque o Estado, por intermédio do Direto também não poderia planejar? Assim, consoante Sarlet e Fensterseifer (2010, p. 21), O Estado Socioambiental: "O Estado Socioambiental aponta para a compatibilidade da atividade econômica com a idéia de desenvolvimento (e não apenas crescimento!) sustentável, de modo que a "mão invisível" do mercado seja substituída necessariamente pela "mão visível" do Direito".

A Constituição Federal de 1988 evidencia que serão/seriam criados planos para a educação ${ }^{3}$, cultura ${ }^{4}$ e juventude ${ }^{5}$. Ainda, pela leitura do citado documento legal, verifica-se que existe a referência da criação de diversos planos, especialmente para a área econômica, almejando o tão pugnado desenvolvimento da Nação: artigos: 174; $188 ; \S 3^{\circ}$ do art. 212 e $214 ; \S 3^{\circ}$ do art. $215 ; \S 8^{\circ}$ do art. 230 . Contudo, percebe-se que não existe referência expressa em dispositivo que versa sobre o meio ambiente a tal fato. Embora existam pensadores que reputem como uma difícil tarefa o planejamento nos tempos atuais, uma vez que se vive em um ambiente fluído e instável - Bauman - a natureza não pode ser refletida como uma interação humana, mas sim com seus ritmos e 
preceitos, assim, o planejamento das ações humanas sobre o meio ambiente é necessário.

[...] Um ambiente líquido-moderno é inóspido ao planejamento, investimento e armazenamento de longo prazo. De fato, ele tira do adiamento da satisfação seu antigo sentido de prudência, circunspecção e, acima de tudo, razoabilidade. A maioria dos bens valiosos perde seu brilho e sua atração com rapidez, e se houver atraso eles podem se tornar adequados apenas para o depósito de lixo, antes mesmo de terem sido desfrutados. (BAUMAN, 2008, p. 45).

O relevante dessa proposta concentra-se no questionamento sobre aquilo que está constituído, almejando a sua reformulação/rediscussão, pois no instante em que o indivíduo questiona a finalidade daquilo que está estabelecido é sinal suficiente de que a sociedade carece de um fim com o qual se identificar. "A racionalidade cognitivoinstrumental da modernidade aparece como a causa principal da crise ambiental, reclamando a constituição de uma nova racionalidade social, aberta à incerteza, ao risco, à diversidade e à diferença". (LEFF, 2004, p. 54).

Por tudo isso, tendo por escopo essencial a possibilidade de planejar objetivos e metas com o escopo de preservar/conservar o meio ambiente, propõe-se a estruturação do Plano Nacional de Meio Ambiente. Para muitos pode ser apenas mais um calhamaço de papel, todavia, para os agentes políticos será um guia e para a sociedade civil organizada um instrumento de luta e zelo aos recursos naturais que certamente repercutirá na qualidade de vida dos seres humanos, bem como de todos os seres vivos.

\section{CONSIDERAÇÕES FINAIS}

A concepção do Estado está sendo modificada: aos poucos deixa de ser um Estado de Direito para ser um Estado Socioambiental de Direito. Essa mutação conceitual exige que práticas condizentes sejam desenvolvidas, especialmente sobre o meio ambiente.

Verifica-se que diversos fatos atinentes ao meio ambiente, podem ser entendido como problema público - saneamento básico, lixo, desmatamento -, uma vez que quanto pior for sua condição, proporcionalmente piores serão os reflexos sobre os seres humanos. Dessa forma, cabe ao Estado, por meio de seus agentes, refletir sobre políticas públicas oportunas para a preservação/conservação dos recursos e serviços naturais.

Assim um Plano Nacional de Meio Ambiente pode compilar todos esses anseios, pois permitirá que discussões amplas definam metas e objetivos com o fim de preservar os recursos naturais.

Nos moldes do Plano Nacional de Educação, em que são realizadas conferências e debates com diversos setores da sociedade, o Plano Nacional de Meio Ambiente, poderia definir metas a serem atingidas em determinado tempo. Por exemplo: implementação efetiva, a partir de 2016, da disciplina curricular de educação ambiental; ou, que até 2015 todas as sacolas plásticas deverão ser banidas do mercado.

Um Plano Nacional de Meio Ambiente desencadearia maiores discussões sobre o meio ambiente possibilitando que estados e municípios se motivassem a estruturar tal documento permitindo, dessa forma, que ações locais repercutissem sobre o global. Por exemplo: no caso de Caxias do Sul poderiam existir metas para a despoluição dos córregos, arroios e rios do Município, ou sobre a supressão de habitações localizadas em áreas consideradas de preservação permanente. 
As políticas voltadas para o meio ambiente como são desenvolvidas atualmente possuem sua função e certamente proporcionam resultados. Entretanto, no instante em que se constrói um trabalho baseado no planejamento e na definição clara de metas e objetivos - foco principal de um plano - maior segurança jurídica e credibilidade serão atribuídas aos agentes políticos, permitindo que as ações voltadas ao meio ambiente se consolidem no tempo.

Percebe-se que, atualmente, as realizações voltadas à preservação/conservação dos recursos naturais são usadas como plataformas políticas de governo e não como políticas de estado. As questões ambientais não podem ser pugnadas como os embates trabalhistas, a reflexão sobre aquelas deve ser mais ampla, pois envolvem não apenas uma categoria social, mas sim toda a coletividade.

Esse trabalho buscou evidenciar que políticas públicas voltadas ao meio ambiente são uma ferramenta adequada de atuação dos agentes políticos, tendo em vista a estrutura atual do Estado e por ser a questão ambiental um aparente problema público. Assim, um Plano Nacional de Meio Ambiente poderia conformar todas essas peculiaridades em um único documento: possibilitando que o meio ambiente não seja refletido em curto prazo, mas sim em longo prazo e não apenas como proposta de governo, mas como uma ação de Estado, cujos resultados deverão ser alcançados, para possibilitar, ao menos teoricamente, a melhoria da vida dos seres humanos.

\section{REFERÊNCIAS}

AZEVEDO, Plauto Faraco de. Ecocivilização - Ambiente e direito no limiar da vida. Revista dos Tribunais: São Paulo, 2008.

BAUMAN, Zygmunt. Vida para o Consumo. Tradução Carlos Alberto Medeiros. Rio de Janeiro: Jorge Zahar Editor, 2008.

BECK, Ulrich. Sociedade de risco - Rumo a uma outra modernidade. Trad. Sebastião Nascimento. São Paulo: Ed. 34, 2010.

BERGUE, Sandro Trescastro. Modelos de Gestão em Organizações Públicas. Caxias do Sul: EDUCS, 2011.

\section{BRASIL. Constituição da República Federativa do Brasil, de 05 de outubro de} 1988. Disponível em Planalto:

http://www.planalto.gov.br/ccivil_03/constituicao/constitui\%C3\%A7ao.htm. Acessado em: 02 de janeiro de 2011.

Plano Nacional de Educação. Disponível em:

http://portal.mec.gov.br/index.php?option=com_content\&view=article\&id=16478\&Ite mid=1107. Acessado em 23 de dezembro de 2011.

Lei n. ${ }^{\circ}$ 6.938/81. Disponível em Planalto:

http://www.planalto.gov.br/ccivil_03/leis/L6938.htm. Acessado em: 29 de dezembro de 2011.

Lei n. 9.795/99. Disponível em Planalto:

http://www.planalto.gov.br/ccivil_03/Leis/L9795.htm. Acessado em: 29 dezembro de 2011. 
Lei n. ${ }^{\circ}$ 12.343/10. Disponível em Planalto:

http://www.planalto.gov.br/ccivil_03/_ato2007-2010/2010/lei/112343.htm. Acessado em: 03 de janeiro de 2011.

Plano Nacional de Cultura. Disponível em:

http://www.cultura.gov.br/site/categoria/politicas/plano-nacional-de-cultura/. Acessado em 23 de dezembro de 2011.

BRYNER, Gary C. Organizações públicas e políticas públicas, pp. 315-333. In: PETERS, B. Guy; PIERRE, Jon (Orgs.). Administração pública: coletânea. São Paulo: Ed. UNESP; Brasília: ENAP, 2010.

CANOTILHO, José Joaquim Gomes. Estado Constitucional Ecológico e Democracia Sustentada, pp. 493-508. In: SARLET, Ingo Wolfgang (Org.). Direitos fundamentais sociais: estudos de direito constitucional, internacional e comparado. Rio de Janeiro: Renovar, 2003.

FENSTERSEIFER, Tiago. Direito Fundamentais e Proteção do Ambiente: A dimensão ecológica da dignidade humana no marco jurídico-constitucional do Estado Socioambiental de Direito. Porto Alegre: Livraria do Advogado, 2008.

FRANCO, José Gustavo de Oliveira. Direito Ambiental - Matas Ciliares. Curitiba: Juruá, 2005.

KLIKSBERG, Bernardo. Como modernizar o estado e formar os gerentes sociais necessários? Algumas sugestões para a ação, pp. 436-451. In: MARRODÁN, Carlos Losada i (Ed.). De burocratas a gerentes? As ciências da gestão aplicadas na administração do Estado. Vitória: ESESP, 2009.

KLOEPFER, Michael. O caminho do Estado Ambiental? A transformação do sistema político e econômico da República Federal da Alemanha através da proteção ambiental especialmente desde a perspectiva da ciência jurídica, pp. 39/72. In: SARLET, Ingo Wolfgang (Org.). Estado Socioambiental e Direitos Fundamentais. Porto Alegre: Livraria do Advogado, 2010.

LEFF, Enrique. Complexidade, Interdisciplinaridade e Saber Ambiental, pp. 19-51. In: PHILIPPI JR., Arlindo; et al. (Ed.) Interdisciplinaridade em Ciências Ambientais. São Paulo: Signus Editora, 2000.

Aventuras da epistemologia ambiental - da articulação das ciências ao diálogo de saberes. Trad. Gloria Maria Vargas. Rio de Janeiro: Garamond, 2004.

OLIVEIRA, José Antônio Puppim de. Repensando políticas públicas: por que frequentemente falhamos no planejamento, pp. 189-204. In: MARTINS, Paulo Emílio Matos; PIERANTI, Octavio Pena (Orgs.). Estado e Gestão Pública - visões do Brasil contemporâneo. Rio de Janeiro: Editora FGV, 2006.

PFAFFENSELLER, Michelli. Gestão Ambiental na Administração Pública. In: CUSTÓDIO, André Viana; BALDO, Iumar Júnior (Orgs.). Meio Ambiente, Constituição e Políticas Públicas. Curitiba: Multideia, 2011. 
SARLET, Ingo Wolfgang; FENSTERSIFER, Tiago. Estado socioambiental e mínimo existencial (ecológico?): algumas aproximações, pp. 11-38. In: SARLET, Ingo

Wolfgang (Org.). Estado Socioambiental e Direitos Fundamentais. Porto Alegre: Livraria do Advogado, 2010.

SARAVIA, Enrique. Introdução à teoria da política pública In: SARAVIA, Enrique;

FERRAREZI, Elizabete. Políticas Públicas: coletânea. V. 1. Brasília: ENAP, 2006.

SECCHI, Leonardo. Políticas Públicas: conceitos, esquemas de análise e casos práticos. São Paulo: Cengage Learning, 2010.

SUBIRATS, Joan. Definición del problema. Relevancia pública y formación de la agenda de actuación de los poderes públicos, pp. 199-218. In: SARAVIA, Enrique;

FERRAREZI, Elizabete. (Orgs.). Políticas Públicas: coletânea. V. 1. Brasília: ENAP, 2006.

WAAL, Francis. A Era da Empatia - Lições da natureza para uma sociedade mais gentil. Trad. Rejane Rubino. São Paulo: Companhia das Letras, 2010.

\footnotetext{
${ }^{1}$ Art $5^{\mathbf{0}}$ - As diretrizes da Política Nacional do Meio Ambiente serão formuladas em normas e planos, destinados a orientar a ação dos Governos da União, dos Estados, do Distrito Federal, dos Territórios e dos Municípios no que se relaciona com a preservação da qualidade ambiental e manutenção do equilíbrio ecológico, observados os princípios estabelecidos no art. $2^{\circ}$ desta Lei.

Parágrafo único - As atividades empresariais públicas ou privadas serão exercidas em consonância com as diretrizes da Política Nacional do Meio Ambiente.

${ }^{2}$ Art. $3^{\circ}$ Como parte do processo educativo mais amplo, todos têm direito à educação ambiental, incumbindo:

I - ao Poder Público, nos termos dos arts. 205 e 225 da Constituição Federal, definir políticas públicas que incorporem a dimensão ambiental, promover a educação ambiental em todos os níveis de ensino e o engajamento da sociedade na conservação, recuperação e melhoria do meio ambiente;

${ }^{3}$ Art. 212. A União aplicará, anualmente, nunca menos de dezoito, e os Estados, o Distrito Federal e os Municípios vinte e cinco por cento, no mínimo, da receita resultante de impostos, compreendida a proveniente de transferências, na manutenção e desenvolvimento do ensino.

[...].

$\$ 3^{\circ}$ A distribuição dos recursos públicos assegurará prioridade ao atendimento das necessidades do ensino obrigatório, no que se refere a universalização, garantia de padrão de qualidade e equidade, nos termos do plano nacional de educação. (Redação dada pela Emenda Constitucional no 59, de 2009). Art. 214. A lei estabelecerá o plano nacional de educação, de duração decenal, com o objetivo de articular o sistema nacional de educação em regime de colaboração e definir diretrizes, objetivos, metas e estratégias de implementação para assegurar a manutenção e desenvolvimento do ensino em seus diversos níveis, etapas e modalidades por meio de ações integradas dos poderes públicos das diferentes esferas federativas que conduzam a: (Redação dada pela Emenda Constitucional no ${ }^{59}$, de 2009)

${ }^{4}$ Art. 215. O Estado garantirá a todos o pleno exercício dos direitos culturais e acesso às fontes da cultura nacional, e apoiará e incentivará a valorização e a difusão das manifestações culturais. [...].

$\$^{\mathbf{0}}$ A lei estabelecerá o Plano Nacional de Cultura, de duração plurianual, visando ao desenvolvimento cultural do País e à integração das ações do poder público que conduzem à: (Incluído pela Emenda Constitucional $\mathrm{n}^{\circ} 48$, de 2005).

${ }^{5}$ Art. 227. É dever da família, da sociedade e do Estado assegurar à criança, ao adolescente e ao jovem, com absoluta prioridade, o direito à vida, à saúde, à alimentação, à educação, ao lazer, à profissionalização, à cultura, à dignidade, ao respeito, à liberdade e à convivência familiar e comunitária, além de colocá-los a salvo de toda forma de negligência, discriminação, exploração, violência, crueldade e opressão. (Redação dada Pela Emenda Constitucional nº 65, de 2010).
} 
[...]

§ 8 A lei estabelecerá: (Incluído Pela Emenda Constitucional nº 65, de 2010)

$[\ldots]$

II - o plano nacional de juventude, de duração decenal, visando à articulação das várias esferas do poder público para a execução de políticas públicas. (Incluído Pela Emenda Constitucional nº 65, de 2010). 